\title{
The Importance of a Community Health Network: An Ethnoanthropological Approach, the Experience of Teaching Demoethnoanthropology of the Degree Course in Nursing at the University of Parma
}

\author{
Sandrino Luigi Marra* \\ Adjunct Professor of Demoethnoanthropology, Degree Course in Nursing, University of Parma, Italy \\ ${ }^{\star}$ Corresponding author: Sandrino Luigi Marra, Adjunct Professor of Demoethnoanthropology, Degree Course in Nursing, University of Parma, Italy; Email: \\ sandrinoluigi.marra@unipr.it
}

Received: June 03, 2021; Accepted: June 11, 2021; Published: June 18, 2021

Although Italy has a long history of migration behind it, it seems unable to convey the long experience accumulated over 150 years on its territory. There seems to be a lack of a network of contacts and relationships with communities of different cultures and social distress in the area of health, where there is a virtuous experiment, even well functional, but not really structured in a network. The COVID-19 Pandemic has shown that the inherent weaknesses in the sphere of migration and social hardship, which have worsened in the absence of a community health network; cultural, linguistic, social barriers, of knowledge of services and institutions, have been widened due to the impossibility of travel and the lack of individual institutional references that could provide indications, information and guidance. The creation of a network of contacts for the teaching of Demoethnoanthropology of the Nursing Studies course at the University of Parma has shown how a culturally competent and correct anthropological approach can provide communities with a channel of orientation and adherence through pre-built direct contact. The network of contacts built by the demo-ethnoanthropology course was born in the year 2013, when a discussion of involvement of the communities of different cultures of the territory is initiated, in a part of the training course of the course. The idea was to exploit university indications regarding the "Third Mission" by involving the cultural diversity of the area in an interaction between the university, students and communities both in the representative offices of the communities and in the university classrooms. The initiative, much appreciated by the representatives and members of the communities, involved a large part of those present in the territory of the city of Parma and the province. The first meetings brought in the classrooms representatives with an important university education, but also young university students and more. In 2015 we created that series of events known as "Cultural coffee" of the nursing study course, unique cultural encounters in Italy for this type of course held within a hospital dining area, therefore in a context outside the classrooms and open to the public in fact we added an element that was required by the Emilia Romagna region that is, bringing events with multicultural characteristics into common places among ordinary people. Over the years, public meetings and going with students to the associative centers of the communities, including the Islamic culture center of Parma, the Gurdwara Singh Saba associative headquarters, the Zoe pentecostal mission of Parma have increased institutional knowledge of the course and created a vast network of relationships. In order to build community involvement with an intention that is also inclusive, an institutional relationship more dedicated to health has also been initiated, since the same communities, aware of our dual role as teachers and nurses, have begun to ask us questions and requests in this regard. to health, to the approach to care, exposing basic care needs, effectively communicating the lack of an interconnection between community and health institution and seeing in our professional figure a simpler channel of approach.

It has happened that in several cases, single individuals have been advised and guided towards the healthcare receptivity of the hospital structure in particular towards complex operating units (cardiac surgery, cardiology, orthopedics, neurosurgery and others), through simple indications, or help in understanding and solution bureaucratic elements that are more difficult to understand. We have provided indications and advice with a correct approach towards the cultural dimension, taking into account the social, cultural context, of habits and customs, views and interpretation of health with respect to the culture of origin. We well know that care and health can be interpreted and seen not according to a standard, on the other hand health is not a static car in its being, but can be interpreted and welcomed on the basis of very diversified social and cultural rules, but which go and should be always considered competently to be correct. Our undergraduate training in anthropology has been for an advantage, both in building trust and networking relationships, as well as in the help and support of care and health and what at first appeared to be a great openness and trust. Towards us, it has also proved very valuable during the COVID-19 Pandemic the measure of trust was also increased by some particular institutional events, such as the meetings for the creation of the room of worship and silence that saw us present on 3 different occasions together with the representatives of the communities and the general managers of the two health companies of the territory, 

Demoethnoanthropology of the Degree Course in Nursing at the University of Parma.

where we became spokesman and link between the two realities and in this regard I want to remember that the city of Parma alone has the presence of 31,000 people of foreign origin on a housing reality of 200,000 inhabitants, with as many as one hundred and 137 different nationalities, and more than 40 associations of different cultures. It is also true that a relationship of trust of a personal nature has been created, but the fact remains that we have presented ourselves to the communities also as institutions, university and hospital together. Was there even a time when we had some doubts about this, was this personal approach also correct? Could it be an advantage or could it become a double-edged sword, with the risk of creating expectations and even disappointments?

The answers came from a meeting with the former prefect of Parma, Dr. Giuseppe Forlani who removed all doubts, he already Central Director of Civil Services for Immigration and Asylum within the Department for Civil Liberties and immigration from the Ministry of the Interior, thus coming from a training similar to ours but with a very vast and particular background of experience in the field, advised us to continue on the path taken and gave us answers and advice, with an important indication or that the institutions must go to the communities and therefore we were doing this, that the personal relationship that has been created is above all an institutional relationship because in this way we entered the communities a personal form is fine too but it is the input context that unconsciously dictated the rules of the relationship. According to his vision, the extraordinary nature of the relationship of trust could be of great help and importance in the future and we are talking about the summer of 2019. created a moment of important meeting between institutions, the municipality, the prefecture, health authorities and the community itself. There was also a similar request arrived a few weeks later by the Ahmadiyya Muslim Jama'at Italia Association which asked us to help them organize an event of presentation and comparison between the religious, community, philosophical and secular diversity of the territory for thus building a relationship of trust and having a link with hospitals through our people. The event scheduled for March 26, 2020 has been postponed due to the COVID-19 Pandemic. But what may appear as a building of relationships of trust, as the prefect had foreseen, in the Pandemic moment demonstrated all the potential of the network, of how the correct anthropological approach, respectful and culturally competent and prepared, had in fact filled a void dictated by an inexperience of the institutions. The communities have contacted us on many occasions, asking us to help them for particular situations, including indications on prevention systems and methods, such as, on our advice, the closure of the Sikh temple in Parma, the first cult institution in Italy to close the 'access to the faithful, a week before the government decree which imposed an absolute ban on access to places of worship. But there are still many requests for the recovery of the bodies or to understand the procedures for managing them and personal effects. But again the participation in the construction of the dedicated site www.oltreemergenze.com in which we provided part of the communications in a different language and we placed ourselves as referents for some procedures. These are just a few examples of the work done.

What does all this prove? First of all, that cultural diversities are in fact largely outside the information context of care and health, that the absence of a system of interconnection between institutions and communities has created a vacuum, which has become a major problem in receiving information and providing actions. at a time when it was in the most complete lockdown. This demonstrated the need for territorial community healthcare, which not only approaches cultural diversity but also social discomfort, as demonstrated by Emergency NGO. The reality of the NGO of which i'm also a volunteer on the project in Milano, shows that in order not to leave anyone behind, there is a need for an institution that enters into community realities, that knows the cultures, that is culturally formed and prepared, that has a solid basis to be able to relate correctly with these. The structure as it is today, demonstrates that at the base there is a void, holes in the institutional mesh that puts in difficulty the realities of different cultures and beyond, that the simple approach with the brochure or flyer in the language is not enough. The construction of a network of relationships with a strong anthropological and intercultural characteristic in the small of a reality like Parma, with only two individuals myself and my colleague Murekabiri with the help of the communities and the network of built relationships, has shown that an intercultural service on the territory, which embraces cultural diversity and social discomfort, can guarantee people not only the possibility of real and correct information but above all equality in care and assistance, remembering that it is from the territory, from the fabric of this that you can improve access to care, adherence to it and also create a valid system of social inclusion. In a small way, this experience has shown that the method used, which in fact is the Canadian one, can be functional, and is required of us, even before the pandemic by the WHO 2020/2030 agenda and is moreover in the directives of the UN. Therefore, concluding if the network built with an anthropological and intercultural approach system has given good results even if in the small of our experience in a medium-sized city, the same system increased through culturally competent elements, organized at an institutional and service level, can achieve important local, regional and national results.

\section{Citation:}

Marra SL (2021) The Importance of a Community Health Network: An Ethnoanthropological Approach, the Experience of Teaching Demoethnoanthropology of the Degree Course in Nursing at the University of Parma. Integr J Nurs Med Volume 2(2): 1-2. 